\title{
A EXPERIÊNCIA DA ANCESTRALIDADE NA BASE DA EDUCAÇÃO ESCOLAR INY
}

\author{
Maria do Socorro Pimentel da Silva ${ }^{1}$ \\ Mônica Thereza Soares Pechincha ${ }^{2}$
}

\section{RESUMO}

O presente texto propõe uma discussão, pautada nas experiências de professoras e professores Iny no Curso de Educação Intercultural da UFG, acerca de questões como "a perda da cultura" e sua relação com dilemas que seu povo enfrenta, especialmente com os mais jovens, como as mortes autoprovocadas. Aborda o papel da comunidade e, principalmente, da experiência da ancestralidade e do sentimento de pertencimento refletidos na ação de uma escola descolonizadora. Mostra como estes dilemas repercutem nos diálogos travados e nas reflexões de professores e professoras Iny em suas pesquisas e em seus esforços de construção de uma escola própria.

PALAVRAS-CHAVE: Povo Iny. Interculturalidade. Ancestralidade. Escola indígena.

\section{ABSTRACT}

This paper proposes a discussion, based on the experiences of Iny teachers in the UFG Intercultural Education course, on issues such as "the loss of culture" and its relationship with dilemmas faced by their people, especially with the younger ones, as self-defeating deaths. It addresses the role of the community and, above all, the experience of ancestry and the sense of belonging reflected in the actions of a decolonizing school. It shows how

1 Doutora em Linguística Aplicada ao Ensino de Línguas pela Pontifícia Universidade Católica de São Paulo. Pós-doutorado em Linguística pela UNICAMP. Professora do Núcleo Takinahakỹ de Formação Superior Indígena (NTFSI) e da Pós-Graduação em Letras e Linguística/UFG. Goiânia, GO, Brasil. E-mail: smariapimentel@yahoo.com.br.

2 Doutora em Antropologia pela Universidade de Brasília (UnB). Professora da Faculdade de Ciências Sociais e do Programa de Pós-Graduação em Antropologia Social (PPGAS) da Universidade Federal de Goiás (UFG). Goiânia, GO, Brasil. E-mail: ppantanalmonica@hotmail.com. 
these dilemmas resonate in the dialogues held and in the reflections of Iny teachers in their research and in their efforts to build a school of their own.

KEYWORDS: Iny people. Interculturality. Ancestry. Indigenous School.

\section{Apresentação}

O que nos motiva a escrever este artigo é a tentativa de aproximação a certas proposições das professoras e professores indígenas no diálogo intercultural que travamos em nossa participação no Curso de Educação Intercultural da UFG, aqui especificamente sobre o que elas e eles têm chamado de "retomada" da cultura frente a desafios que têm enfrentado as gerações mais jovens. Partimos do suposto de que aquilo que elas e eles aludem como sendo suas culturas e tudo o que abarcam sobre este conceito intercultural, já que circulante em seus contextos a partir das interpelações históricas que lhes colocaram esta questão diverge do que temos como conceito acadêmico e antropológico, apesar das assimilações recíprocas e distâncias.

Certamente, esta suposição ecoa a distinção feita por Carneiro da Cunha (2009) entre cultura e "cultura". A autora distingue cultura com e sem aspas, esta última forma remetendo aos esquemas próprios interiorizados que dão sentido à ação e percepção indígenas, enquanto a "cultura", que grafa com aspas, refere-se a um metadiscurso articulado entre os indígenas a partir da sua ampla circulação no mundo pós-colonial, ligado ao sistema interétnico, bem como ao posicionamento político indígena neste sistema. Longe de pretendermos relegar a segundo plano a politização dos usos da "cultura", nossa indagação dirige-se mais a um de seus corolários, especificamente o do que, na experiência indígena, se estaria perdendo quando lamentam e dizem recear a "perda da cultura".

No que se segue, vamos examinar essas proposições a partir do caso Iny/Karajá, ainda que não lhes seja exclusivo. O fazemos tanto pelo conhecimento aprofundado que uma das autoras deste texto acumula sobre esse povo, a quem estuda e com quem convive há décadas, bem como por estas questões se nos apresentarem não só, mas também, pela conjuntura sociocultural que cerca os dilemas que vêm sofrendo com mortes "autoprovocadas" de seus jovens nos últimos anos. Estas últimas não são o tema deste texto, mas 
suscitam discussões em torno de alterações em seu modo de vida e organização, temas que perpassam a reflexão sobre a construção própria do projeto de educação escolar Iny, que é o foco das ações na formação de professores no curso de Educação Intercultural da Universidade Federal de Goiás.

Algumas complexas afirmações desse povo nos guiam em nossas reflexões. As primeiras delas são considerações em torno de uma dimensão de relação das pessoas com uma "realidade invisível", que assim denominamos precariamente, na ausência de um léxico preciso que nos permita qualificá-la conceitualmente. Diante do entendimento conceitual de cultura enquanto experiência simbólica e, portanto, cognitiva, de linguagem e psíquica, nos deparamos com a proeminência de relações sensíveis, traduzidas para português como "espirituais" ou também como de relações espirituais com a "natureza". Além desta dimensão, se acresce como questão de interesse em nossas reflexões interculturais a afirmação dos Iny de que, se em suas comunidades não se fala mais a língua indígena, ou não se cumprem ritos originários, não se tem a cultura. Estas afirmações se conjugam com a preocupação de professoras e professores Iny de que estejam ou possam vir a "perder" sua cultura.

Com efeito, existe também uma reflexão própria sobre as transformações, com o contato intercultural, naquilo que consideram como inevitável ou mesmo como parte do dinamismo intracultural. Tudo isso guarda relação com a transmissão de saberes, que são tema central no diálogo sobre as ações pedagógicas no âmbito de um curso de formação de professoras e professores indígenas. Nessa percepção, a educação situa-se, prioritariamente, nos direitos dos povos indígenas, na vivência cultural; na consideração do saber e das experiências ancestrais; no cuidado com as crianças e com os jovens; na inclusão de projetos sociais/comunitários. Estes são os paradigmas centrais dos projetos políticos pedagógicos feitos por docentes indígenas no curso de especialização em educação intercultural e transdisciplinar: gestão pedagógica.

Partimos da constatação da mobilização de professoras e professores em direção à retomada cultural, com visíveis repercussões em suas comunidades. Esta mobilização, não obstante, se contrapõe à reclamação que fazem de não estarem os mais jovens cumprindo normas culturais, o que pode resultar em efeitos deletérios. É a partir desta contraposição que indagamos sobre o quê, na contemporaneidade, está desafiando a manutenção de relações 
respeitosas internas, segundo a ética Iny, e que é, sem dúvida, uma das maiores de suas preocupações. Nossa hipótese é a de que a escola e a religião não indígena jogam um papel crucial nesta desestabilização. Mas, se nem escola nem missões são interferências recentes nas comunidades indígenas, por que hoje tal desestabilização estaria fugindo ao controle em algumas delas? Não podemos responder diretamente a esta questão, de forma que o objetivo deste texto é pontuar a maneira como os Iny lidam com e enfrentam este problema em seus projetos de pesquisa e extensão e de construção de uma escola própria.

\section{Experiência da ancestralidade}

Não é sem interesse a ênfase que as professoras e professores Iny atribuem ao tema do "respeito" e da "lei" de sua cultura quando têm em questão a transformação da ação da escola em favor do futuro e do bem-estar de suas comunidades. Interessa sublinhar que esses indígenas falam dessas relações de respeito em termos de saberes ancestrais, que dependem de suas formas próprias de transmissão. O sabedor e a sabedora de hoje trazem em sua sabedoria o saber dos ancestrais, avô/avó/tio/tia. É uma rede epistêmica que não se quebra. Os sábios de hoje não são novos autores, mas continuadores. Por exemplo, contamos com relatos de homens Iny que dizem terem aprendido todas as regras do Hetohokỹ, ritual de iniciação masculina, com seu pai, que aprendeu com seu avô, e assim o foi anteriormente desde tempos imemoriais. Neste movimento não surgem novas "escolas", mas novos sábios e sábias que perpetuam o já existente.

É observável, também, que, para os Iny, a lei supõe aquela "realidade não visível", que não é "paralela", pois não é demarcada por uma linha que separaria interior e exterior, de cultura e de corpos e sujeitos. Entendemos aqui tanto as relações espirituais, quanto a atualização de uma ética Iny de relações, em termos do que chamaremos de uma "experiência da ancestralidade". O termo "ancestralidade" sem dúvida está ligado ao processo temporal, mas, quando falamos nesta "experiência de ancestralidade", não queremos remeter a algo passado que não existe mais e que tem que ser reinventado, pois os pesquisadores e as pesquisadoras Iny que participam do curso de Educação Interultural, quando falam de saberes e práticas ancestrais, falam em termos de "acordar", de 
despertar algo que está ali, mas deixado em certa medida de lado. Entendemos que não há nisto um sentido de nostalgia conservadora, nem tampouco de restaurar um tempo que não é mais como no passado. Eles e elas mesmas dizem que não teria sentido nem lógica que se reproduzisse um passado artificialmente. De outra forma, esta experiência é mais perceptível enquanto ligada ao campo das emoções, como se pode vislumbrar no seguinte relato de uma das autoras do presente texto:

reviver a memória coletiva constitui-se para os Karajá de Buridina um paradigma importante na retomada de conhecimentos. Certa vez, levei para essa comunidade o livro Linguagem Especializada: Mitologia Karajá, que foi produzido durante os encontros de professores, cantores, dançadores, pintores, ceramistas, historiadores Karajá, etc. O livro foi escrito em Karajá, nas falas masculina e feminina e em português. Distribuí o livro em todas as casas da comunidade e, no mesmo dia, à tardinha, voltei à aldeia. Para minha surpresa, muitas famílias estavam reunidas lendo e contando as histórias do livro para seus filhos e netos. Avós e pais se lembraram de outras histórias, recuperaram parte de histórias esquecidas, aqueceram a memória, sentiram saudades de muitos momentos de aprendizagem vividos com seus familiares. Muitas dessas histórias contam sobre a origem do mundo, do homem, das pinturas; outras falam da origem da vida, da morte, de como aprenderam a agricultura, os rituais, os cantos, como também a caçar, a cuidar da natureza e preservá-la.

A atitude deles não eram de avós contando uma história, mas de acesso aos saberes ancestrais.

Recentemente, um jovem Karajá, casado, sabendo da existência desse livro, quis adquiri-lo com a intenção de conhecer as histórias nele registradas. Dei-lhe um exemplar. Dias depois, ele me ligou e me contou que leu algumas narrativas para sua avó, e esta ficou muito feliz e entusiasmada, tendo ainda contado para ele outras histórias. O mesmo Karajá leu algumas histórias também para seus filhos que ficaram curiosos e queriam saber mais dos fatos narrados. Adormeceram 
com o pai contando as histórias. Este pai, que ainda é muito jovem, quer conhecer muitas outras histórias de seu povo. Um conhecimento que não aprendeu quando pequeno, mas agora deseja adquiri-lo. E, ao ter acesso a esse saber, terá conhecimento de uma parte muito importante da sabedoria iny. Quando ele me contou sobre esse evento, falava com muita alegria e com desejo de acessar os saberes de seu povo. (PIMENTEL DA SILVA, 2017).

Percebemos no contexto do curso de Educação Intercultural, por um lado, uma grande ansiedade indígena com a "perda da cultura" e, por outro, a emoção indescritível quando sentem revitalizadas suas práticas e saberes culturais. Para nós, um momento de descolonização, sobretudo em como confronta a ação colonizadora da escola que lhes foi imposta. Para eles, a experiência de reativar algo que estava ali "adormecido" - eles sempre dizem que "não morreu" - mas cuja experiência lhes é muito particular. Não se assemelha com o sentimento que temos em ver o passado, ou a diversidade cultural em uma experiência de contemplação histórica, estética, educativa e mesmo afetiva ou religiosa. O que queremos sugerir é que, na experiência Iny, opera uma conexão entre os seres - humanos e não-humanos, incluindo as coisas "materiais" - de uma forma tão entrelaçada e, para nós, tão inacessível, que só podemos remetê-la àquela indivisão entre visível e invisível e entre interno e externo acima mencionada. Assim como a reiteração da forma considerada correta de se viver e de travar relações. A tudo isto estamos chamando de experiência ou sentimento de ancestralidade.

A lei, para os Iny, também subsome aquela "realidade não visível", que atinge o ápice de intensidade no ritual masculino do Hetohokỹ, que é ocasião para a renovação da relação com espíritos de diversas naturezas: os mortos, os aõni, de condução masculina no ritual, mas a que a todos e todas estão sujeitos. Realidade não visível, que envolve conhecimentos e práticas, corpos, sujeitos e artefatos. Como os paramentos rituais, e outros que foram por nós incluídos na categoria "artesanato".

O importante de se ressaltar é que tudo das ordens que chamamos de material e espiritual está entrelaçado na produção das pessoas Iny. Os professores e as professoras Iny falam sobre este entrelaçamento quando comparam a ideia de "transdisciplinaridade" com a forma de transmissão de saberes ancestrais. Estes não são, 
em sua visão, compartimentalizáveis como conhecimentos que não se tocam e não se implicam mutuamente. Não se pode entender a transmissão de conhecimentos Iny sem conectar as múltiplas dimensões de se conhecer, de se fazer Iny e de usar esta sabedoria para manter a forma boa e correta de viver, apesar das interferências do contato progressivo com o mundo dos brancos.

Estes saberes precisam ser praticados, pois o saber vive no fazer. É praticando o saber que se o guarda e que se garante a sua circulação. Muitos professores Iny, por exemplo, com suas pesquisas, se surpreendem por não saberem muitos conhecimentos, porque não os praticaram ou porque não viram esses saberes serem praticados. Muitos dizem: "nem sabia que esse saber existia. Não aprendi quando jovem ou criança".

Quando o pesquisador Iny começa a ter acesso a esses saberes, percebe-se neles sentimentos de alegria, de satisfação de pertencimento, que é o que estamos chamando de experiência da ancestralidade. É esse sentimento que se percebe durante o Hetohokỹ, ritual de passagem do menino para adolescência, compreendido pelos Iny como o ritual de maior expressão espiritual. Além da beleza, do colorido dos adornos, da diversidade dos grafismos usados nos corpos dos participantes e do longo preparo desse ritual, há a concentração diversificada e intensa de Anoni Anoni e Worysỹ (espíritos).

\section{A busca do conhecimento Iny}

Uma das experiências do curso de educação intercultural bem-vindas pelos professores e pelas professoras Iny é o estudo pela pesquisa. Este tipo de educação possibilitou-lhes rever valores e busca alternativa frente ao modelo escolar hegemônico vigente em nosso país. Para dar conta desse desafio, torna-se necessária a construção de práticas pedagógicas fundadas em perspectivas inovadoras de congregação de todos e todas envolvidas nos processos de retomada de valores e saberes. Exige-se, ainda, a elaboração de novos conhecimentos que se expressam em ideias, conceitos, paradigmas imprescindíveis à construção de matrizes epistêmicas interculturais, capazes de incorporar as experiências da ancestralidade, apontando, assim, para outro projeto de educação, não mais fundamentado em estruturas governadas pelas concepções monolíngue, monocultural e disciplinar, que sempre excluíram os saberes indígenas da escola. 
Temos na postura da educação intercultural crítica uma concepção de ensino que enfatiza a problematização e a reproblematização de quem se interroga movido pela curiosidade e inquietação. A contextualização da realidade, das questões, provoca leituras multirreferenciais que ultrapassam a disciplinaridade. Neste sentido, parece-nos que a questão da dialogia ancestral e da esperança são ângulos que permitem construir o encontro cultural de retomada de saberes, valores e respeito.

O que se almeja, é um processo de descentramento da autoridade disciplinar. Ou seja, o que está em jogo é que outras vozes reivindicam e conquistam espaço para se fazerem ouvir, se projetarem e legitimarem seus conhecimentos. A luta pela afirmação das diferenças, pela alteridade, são algumas características da contemporaneidade que põem em questão também a abordagem transdisciplinar clássica, que ao se fundamentar no paradigma da disciplinaridade, preserva a ideia do conhecimento científico como única forma de conhecimento válido, mesmo se espalhando. Desse modo, o diálogo epistêmico restringe-se aos saberes ditos científicos. Isso continuará provocando a exclusão dos saberes indígenas, por exemplo, provocando mais epistemicídio. Isso provoca medo nos intelectuais indígenas. $\mathrm{O}$ medo de perder a cultura. Isso não reflete nenhum saudosismo, mas realidade pura. São eles que sentem essas dores.

A proposta da educação intercultural e transdisciplinar faz esse chamado, quando se realiza em práticas de demandas sociais e de retomadas culturais, colocando nessa contextualização leituras outras, como, por exemplo, esticar saberes, retomada cultural, temas contextuais intraculturais, interculturais e transculturais. Isso são evidências de sinais de uma nova e dupla ruptura epistemológica que é a do reencontro da ciência científica com as outras ciências, sem clausuras e apelidos coloniais, como as tais etnociências.

Nessa percepção de educação, os pesquisadores e as pesquisadoras Iny buscam conhecimentos em sua aldeia e em outras, e os coloca em pauta em animadas discussões no âmbito do curso de Educação Intercultural, além de muitas ocasiões que se estendem com as suas pesquisas e reflexões em suas comunidades. Esta nova forma de remexer em seus conhecimentos tem causado impacto e transformações docentes, como a avaliação do tipo de conhecimentos que a escola lhes ofereceu no passado não distante. Como disse o 
professor Nelsom Wanahuwa: "Nunca mais serei um professor disciplinar. A disciplinaridade mata nossos conhecimentos".

Diferentemente do saber ocidental, que separa oralidade e escrita, entre os Iny, a oralidade sempre está junto do saber artesanal, do saber espiritual, do saber ecológico, por exemplo. Isto porque o saber indígena não é só oral, ou não é apenas ensinado oralmente, pois existem outras formas e práticas entrelaçadas: artesanal, corporal, estética etc. Toda a geopolítica Inybdèdỹkỹnana (sabedoria Iny) é a do saber fazer, é a do praticar o saber: dançar, cantar, "artesanar". Se isto não acontece, surge o sentimento da perda cultural.

O entrelaçamento e a prática dos saberes da oralidade, da pintura, do grafismo, da produção artesanal possibilitam a constituição humana fundada na ancestralidade, resistindo à pressão dos processos de dominação da modernidade/colonialidade e da mentalidade escolarizada, de base eurocêntrica.

Acreditamos que a arte Iny é um dos principais meios de movimento da sabedoria, ou da experiência da ancestralidade, de tal forma que ações pedagógicas dinamizadas na pesquisa e na produção artística se revelam como prioridades eleitas pelos professores e professoras, de evidente aspecto terapêutico, de vinculação do estético com o ético, da valorização do belo e de expressão da beleza de ser Iny.

As ritxoko, por exemplo, simbolizam aspectos dos rituais, de histórias/mitos, que guardam saberes importantes, como o ensinamento de como cuidar da natureza, de como não agredir o meio ambiente. É por meio da feitura dessa atividade epistêmica que meninas Iny aprendem, além de produzi-la, muitos outros conhecimentos, todos necessários à formação feminina. As mulheres educam os filhos, guardam os saberes, fazem o conhecimento circular nas comunidades e no mundo por meio da arte; documentam o saber pelo fazer cultural; sustentam a estrutura familiar e comunitária. São responsáveis por saberes especializados. Produzem e vendem as peças de artesanato e, com isto, participam também do sustento familiar. Contribuem com o ingresso financeiro nas comunidades. Assim, são muito amplas as vinculações da arte com a dinamização da experiência ancestral, além de usos práticos que se articulam com a produção artística.

A arte sempre retoma saberes, expõe outros, coloca muitos saberes em circulação. A epistemologia artesanal é valorosa na manutenção da sabedoria Iny, na conexão com as experiências 
ancestrais. As artesãs não só ensinam modelar uma ritxoko (boneca de barro), como retomam nesse ensinamento histórias de sabedorias ancestrais, que se renovam nesse fazer.

As mulheres e os homens mais velhos são os guardiões da sabedoria ancestral, são bibliotecas, como dizem os Iny. Na medida em que algum desses saberes não é mais praticado, eles caem na invisibilidade, ou seja, não chegam à memória dos jovens. Como se observa na citação de um professor Iny abaixo, onde destaca o respeito, a forma correta de ser Iny e o ensinamento dos espíritos da natureza:

a vida dos jovens Iny (Karajá) a maioria deles (as) vem causando desrespeito contra a sua cultura, como por exemplo, a desobediência aos mais velhos, aos conselhos de suas tias e aos conselhos dos espíritos dos animais que ocorre durante a passagem para o ciclo de vida denominado de jyrè no ritual de hetohokỹ, a festa tradicional da iniciação do jovem para o ciclo de vida de adulto, denominado de weryrybò e wekyrybò na fala feminina, principalmente, meninos. As meninas quebram as regras ou normas de fazer jejum da alimentação, quando, estas passam para o ciclo de vida denominada de ijadòma e ijadòkòma na fala feminina, que é o ciclo de vida das moças, deixam de serem meninas a partir da execução do ritual. Na vida do Iny o respeito é a fonte de manter o equilíbrio de ser Inỹ, o eu e você, ou seja, nós. Na tradução dessa palavra ou significado é a pessoa ter honestidade e hospitalidade. A denominação do povo de Iny quer dizer ser honesto, humilde, ser uma boa pessoa.

... É nessa ideologia ou questão que faço a reflexão sobre a falta de ensinamento da natureza com os jovens de hoje. Quando estamos passando para o ciclo de vida denominada de jyrè, a natureza está fazendo a sua parte de orientar na formação do jovem Iny. Ali estão presentes os espiritos dos animas da região representada pelos jovens Iny, onde, eles cantam dançam cada qual com os seus pares. São nesse momento que a natureza entra para fazer os seus conselhos, a sua participação é para amadurecer a memória do iniciante - jyrè -, traz para o ciclo de vida a fala dos ancestrais, a forma 
de educar, a norma de respeitar o outro e a própria natureza. É nessas condições ou formações que mantenhamos o respeito, a obediência e a forma de ser Inỹ (OLIVEIRA WAHUKÁ, 2015, p. 1, negritos do autor, itálicos nossos).

\section{Lei e respeito}

Para os Iny, "lei" e "respeito" caminham juntos. Em suas etnografias dos Iny, Nunes $(2012,2016)$ registra um aspecto peculiar da conduta esperada e exigida em fases distintas do ciclo de vida. Aqui nos interessa particularmente a observação de que, até antes do casamento, das jovens e dos jovens Iny não se exige a responsabilidade em atividades próprias a adultos, cujo status e obrigações adquirem com o casamento. Antes desta passagem, cabe aos progenitores e aos avós o suprimento de todas as suas necessidades e dos desejos das crianças.

Que as palavras dos parentes passem a entrar no ouvido das pessoas, significa que elas passem a agir com outros em mente. Mas as crianças, como disse, são puro desejo. E também os weryrybò e ijadòòma [em nota: Categorias de idade de, respectivamente, rapazes e moças iniciados e solteiros, geralmente na faixa de 15 a 18 anos], ainda que em menor medida. Enquanto ainda solteiros, eles não têm obrigação de trabalhar, o que eles fazem é motivado principalmente por seu próprio desejo (NUNES, 2016, p. 200).

Nesta citação, fica patente a ideia de transmissão de saberes que devem entrar pelos ouvidos de uma pessoa, que ganha progressivamente a capacidade de ouvi-los. Esta transmissão de conhecimentos e atitudes se conecta com a ideia do sentimento de ancestralidade que acima evocamos. Já as exigências diferentes em cada ciclo de vida, com total liberdade e provimento das crianças e dos solteiros, poderiam nos induzir a especular sobre a relação entre não se cobrar muito, não se esperar que as crianças tenham ouvidos prontos para o conhecimento ancestral e o fato de os jovens não estarem praticando o respeito. Isto, com a ressalva de que, ainda que assim o fosse, não bastaria para entender por que anteriormente 
a atualização da lei e do respeito demonstrou eficácia suficiente, enquanto que na vida atual estaria se enfraquecendo em algumas de suas comunidades entre os mais jovens.

Se é válido recorrermos aos mitos como modelos de comportamento, é interessante observar que, em inúmeros mitos Iny, as personagens em regra estão frente a decisões entre duas possibilidades de ação e realizam justamente a que configura uma desobediência. Acresce-se ainda a observação, na mitologia Iny, de ações que se realizam como a escolha das e dos protagonistas, menos que como imposição, embora não faltem também relatos míticos sobre punições exemplares. Estes motivos míticos permitem a interpretação de que correspondem a um contexto cultural no qual, filosoficamente, se consideraria a liberdade de escolha.

Embora tudo isto leve a pensar que a concepção de cultura Iny é de tal forma que não se fundaria na interdição de desejos, muito mais significativa é a ideia de formação da pessoa Iny a partir de exemplos a serem seguidos. Como se percebe, entre outras ocasiões, no ritual da primeira alimentação de uma criança, que passa a partilhar a mesma comida que os adultos, quando o/a parente convidado/a para fazê-lo, é um ou uma Iny reconhecido/a com portador/a de bom exemplo: ser bondoso/a, respeitoso/a, trabalhador/a, bem sucedido/a, não de riquezas, mas de atitudes.

$\mathrm{O}$ uso da língua Iny e a dedicação com que as professoras e professores conferem ao estudo e produção de material para leitura, em sua língua, também está ligado ao que estamos chamando de "experiência da ancestralidade". Os Iny traçam uma clara relação entre perda da língua e a perda da cultura. Esta implicação é muito ressentida, por exemplo, nas reflexões de professores Xambioá, povo Iny que mais foi compelido ao uso quase exclusivo da língua portuguesa.

Todos os povos Iny contam com pessoas falantes de sua língua materna e do português e com pessoas falantes de apenas uma delas: há crianças e pessoas mais velhas que usam predominantemente a língua Iny, mas o português é de conhecimento geral. Seja pela inevitável necessidade, como também pela desvalorização pela escola convencional, os professores e professoras Iny reclamam da "força" da língua portuguesa e da cultura não indígena e seus efeitos negativos em termos de atualização de transmissão de conhecimentos e de formas de convivência. 
Há repercussão dos usos que se fazem das línguas, por exemplo, na impropriedade de formas de referirem a parentes com o devido respeito, com os termos adequados de parentesco e os tecnônimos, que são por eles e elas considerados como propiciadores das relações de respeito. Como se preocupa um professor Iny:

Havia citado acima que a desobediência com os mais velhos causa o desrespeito à cultura; por que disse isso? É que muitos dos jovens hoje eles (as) não cumprimentam, principalmente os mais velhos (as). O cumprimento está ligado aos conhecimentos dos parentescos, quem são os tios e de que parte, materna ou paterna, mais novo (as) do que o pai ou do que a mãe. Essa forma de cumprimentar não se ouve mais em meios aos Inỹ, e outra é ser chamado pelo nome do filho (a), quando esta é o primogênito, a partir dessa sequência o avo (ó) passa a ser chamado também pelo nome do neto (a), ou seja, avo (ó) do fulano de tal (OLIVEIRA WAHUKÁ, 2015, p. 2).

Os Iny entendem que sua cultura é um conjunto de ações e conhecimentos aprendidos em um tempo primordial sobre o qual narram os seus mitos. Como narra o seu mito de criação, os Iny deixaram um mundo em que não havia morte e diferenças, para um em que as há, apesar de toda a sua beleza. Mas o que ressaltamos como mais relevante é que, mesmo neste mundo para o qual passaram, não se traçou definitivamente uma fronteira entre o interno e o externo da realidade visível e não visível.

Este entendimento da cultura pelos Iny não impede que se possa vivenciar outras experiências culturais, como a dos não indígenas, embora tenha rebatimento tanto no sentimento de perda, quanto nas ações de retomada e no lamento pelo descaso causado pela força da colonialidade.

Ainda assim, há uma teoria Iny de que se pode trocar de perspectivas segundo o contexto-indígena e não indígena-mantendo sob controle a agência em cada uma dessas perspectivas. Esta teoria foi registrada por Nunes (2012) em sua dissertação sobre os Karajá de Buridina, que vivem uma situação em que estão "misturados" de forma intensa com os não indígenas. Como fica claro na fala de Renan Wassuri, citado por Nunes (2009): 
quando a gente vai pra cidade, quando atravessa o portão [da aldeia] ali, tem que tirar a memória indígena, guardar no bolso e colocar a memória de não-índio no lugar [gesticulando com as mãos como se tirasse e colocasse pequenos chips de memória em sua cabeça]. Quando chega pra cumprimentar alguém é "bom dia", "como vão os senhores?", se for uma mulher abraça e dá um beijo no rosto, ou então dá um beijo nas costas da mão. Aí vão saber que quem está ali é um cavalheiro. Porque os índios não se cumprimentam assim, é na distância, não se encostam. Aí quando passa do portão pra dentro tem que tirar a memória do não-índio da cabeça e colocar a memória indígena, que estava guardada [no bolso], no lugar. Aí volta a funcionar do nosso jeito. Então a gente tem que ter essas duas memórias, e as duas são muito importantes pra gente (NUNES, 2009, p. 14).

O perigo está, como adverte Nunes (2016), quando se transpõe este equilíbrio, perigo consonante com a queixa de Wahuká acima citada, assim como das professoras e professores Iny de outras comunidades que não Buridina. É bom ressaltar, conforme Pimentel da Silva (2016), que a comunidade de Buridina vive uma situação de retomada de saberes milenares por meio do projeto de Educação e Cultura Indígena Maurehi, que se iniciou em 1994. Um projeto que conta com apoio dos Iny/Karajá de todas as aldeias (professores/ as, cantores, artesãos, artesãs, desenhistas, narradores de histórias). Esses encontros acontecem anualmente. Conforme Pimentel da Silva (2009), o primeiro encontro feito em Buridina, em 1995, teve por meta iniciar a reconstrução dos lugares de narrar histórias, de produzir artesanato, de fazer os grafismos e as pinturas, de aprender e praticar as danças, de cantar. São lugares do fazer cultural e do falar em língua Iny/Karajá, mesmo em uma comunicação híbrida, de um bilinguajamento, um pensar entre línguas.

De uma ou de outra forma, consideramos que as assertivas dos Iny sobre sua cultura e língua, menos que uma aparente essencialização, tem a ver com o que estamos chamando de experiência da ancestralidade. A crítica já há muito desferida contra a essencialização da cultura e de atributos culturais tem pelo menos dois vetores: um o de que o universo do simbólico é por definição instável, portanto, sujeito a transformações e reinterpretações por 
quem os vive; outra, mais afim à questão da identidade étnica, a de que esta não está colada a um repertório cultural imutável, sem que isto signifique que a diferença não permaneça, mas até que se intensifique e se fortaleça independentemente de distinção cultural. Nem uma nem outra destas postulações parecem recobrir o entendimento Iny. Isto porque, na sua concepção, vários planos da experiência dos seres estão conectados de uma maneira que o conceito simbólico de cultura não comporta inteiramente.

No nosso entendimento, também a língua Iny é entendida por eles enquanto meio imprescindível para se ter ou garantir a cultura, pois se vincula tanto à transmissão apropriada de saberes, quanto à experiência sensível da ancestralidade. O projeto Maurehi da aldeia Buridina, por exemplo, se fez na reconstrução dos espaços epistêmicos/culturais. A língua veio nesse fazer ancestral, no sentimento da força ancestral, na polifonia ancestral de todo o fazer cultural. A língua ganha vida na retomada dos saberes ancestrais. Há aí uma energia poderosa de ligação entre gerações, espaços e tempo.

\section{A escola transforma os jovens Iny?}

De todas as questões apontadas por professoras e professores Iny como relacionadas às tão sofridas mortes autoprovocadas de tantos jovens, cinco são recorrentes. Uma delas é o dinheiro: os jovens querem dinheiro para comprar objetos de desejo, como, por exemplo, celulares, e o não atendimento desse desejo pode resultar nessas mortes; outra é o feitiço, mas alguns dizem que o suicídio provocado por feitiço tem manifestação específica, pois o corpo fica de forma diferente; outra é o controle social não operante: isto se dá, sobretudo, quando os jovens do sexo masculino não recebem mais a educação própria para ser um bom homem, o que está ligado ao que chamam de falta de respeito e de quebra com a espiritualidade, de quebra com a "energia da natureza"; e ainda outra explicação seria a de alguém vítima de paixão amorosa, de índice aparentemente menor.

Escutando essas questões, e as contrapondo ao que temos argumentado neste texto, consideramos que a grande causa dos suicídios é, de fato, o modelo de uma sociedade capitalista imposto à outra. Com isso nascem outros desejos, falta de respeito, abandono cultural. 
Tanto a triste situação das mortes de jovens, quanto os esforços das professoras e professores Iny em retomar a sabedoria ancestral e as consequentes expressões de satisfação de experiência da ancestralidade, as quais estavam se enfraquecendo, se justapõem em suas comunidades. Não é inequívoco que os jovens não apreciem sua cultura, como disse recentemente o professor José Kuriawa da aldeia Macaúba. Este professor é um grande pesquisador dos rituais e das músicas de Hetohokỹ e de Ijasó. Ele está organizando um grande encontro só de homens em uma praia do Araguaia, só para cantar e dançar Ijasò. Ele reconhece que todos gostam, que os jovens também apreciam. Por isso, precisa acontecer. Ou seja, os jovens não abandonam a cultura, mas são impelidos a isso por conta da colonialidade cultural.

Por seu turno, a sementinha de uma educação decolonizadora encontra muitos desafios. O sistema de ensino do Estado é monolíngue e monocultural. As universidades continuam com seus currículos fechados. Todavia, é visível o esforço das professoras e professores Iny para transformar e estão transformando a sua escola. Estão criando uma escola da e para a comunidade, com suas concepções em primeiro plano. Grande é a crítica que ora fazem aos riscos que se corre com o modelo até então operante de educação disciplinar, que tem desferido grande golpe na direção do desaparecimento dos saberes indígenas. Estas reflexões comparecem na fala e na escrita de professores Iny:

Percebi na minha pesquisa que a minha língua indígena serviu na escola apenas como um instrumento facilitador da língua portuguesa. Até hoje alguns professores estão nessa gaiola, ao invés de procurar pesquisar a realidade que envolve o mundo das crianças e também dos adultos e mostrar o valor da nossa cultura, estamos buscando dentro dos livros didáticos que são entregues pela secretaria de educação educar nossos alunos sem discutir. Desta forma, os nossos conhecimentos tradicionais são inferiorizados (KARAJÁ LARIWANA, 2011, p. 10).

Muitos professores estão presos na gaiola do conhecimento disciplinar (KARAJÁ KUHANAMA, 2011, p. 3). 
Essa concepção de transdisciplinaridade e interculturalidade rompe com a educação colonial, pois a educação indígena deve caminhar com seus próprios pés (KARAJÁ TXIARAWA, 2011, p. 08).

De fato, é crescente a compreensão das professoras e dos professores indígenas de que a educação intercultural é, mais que tudo, uma abordagem crítica das imposições que têm vivido ao longo da história e em sua vida atual.

De nossa parte, não sabemos qual a transformação que a escola está gerando nos jovens. Acreditamos, no entanto, que uma movimentação direcionada a renovar positivamente o sentimento de pertencimento dos jovens esteja acontecendo, apesar da intervenção do estado, que insiste em manter uma escola colonizadora. Os professores e professoras Iny mudaram o entendimento restrito que tinham da ação da escola, estão produzindo ideias inovadoras, estão atuando como protagonistas. Não por conta dos saberes ocidentais, mas pela decolonialidade dos seus saberes e por sua retomada. Assim, que afirmam que trabalhar com temas de sua cultura e realidade, o que no curso de Educação Intercultural chamamos de "temas contextuais", é para eles dar uma "aula rica", uma aula de pesquisa, para o crescimento de alunos e professores e para os reais interesses de suas comunidades:

Na disciplina o professor é apenas um prestador de serviço. Na contextualização dos Temas Contextuais os alunos passam a pesquisar e conhecer seus saberes juntamente com o educador e com a comunidade. São assuntos a serem trabalhados para o crescimento dos professores e dos alunos através das pesquisas a serem realizadas tanto na área da qual o educador deseja lecionar, quanto de áreas que são demandas da comunidade e dos alunos (KARAJÁ MAIRU, 2015).

\section{Algumas considerações}

Neste texto, apresentamos algumas questões apontadas pelos/ as pesquisadores/as Iny no que se refere à educação ocidental de modelo disciplinar e à educação intercultural que dialoga com as experiências da ancestralidade. Essas reflexões remetem a dois pontos 
centrais: séculos de epistemicídio, que provocou o desperdício de uma imensa riqueza de experiências cognitivas, artesanais, espirituais, e linguísticas; e a educação intercultural decolonizadora, que se coloca em oposição à proposta de educação hegemônica. Este tipo de educação é vista pelos intelectuais indígenas como possibilidade de retomada de saberes milenares, abrindo, assim, espaços para o combate do epistemicídio, que gerou entre esses estudiosos o medo da perda cultural.

Há, sim, uma ameaça muito grande, pois muitos desses conhecimentos estão fora da matéria, do visível, do exterior, ocupa o espaço da memória. É por isso que os/as Iny dizem: cada sábio/a que morre leva consigo uma biblioteca de nossos saberes. Percepção inconcebível do ponto de vista do mecanicismo positivista da ciência moderna.

O desafio, então, é trazer, cada vez mais, o direito das diferentes formas de conhecimento dos indígenas a uma existência sem marginalização ou subalternidade. Não se trata, portanto, apenas da proposta traduzida como intercultural, mas de desbancar a tradição canônica das monoculturas do saber. A proposta é a superação da perspectiva colonialista de produção do conhecimento, e, assim, questionar a colonialidade em todas as suas dimensões, promovendo a desconstrução das práticas educativas hegemônicas.

Desse movimento vão surgir, ou estão surgindo, novos movimentos de educação decolonial. Por enquanto, a visão e a ação para a decolonialidade são orientações que coexistem em tensão com outras visões e sistemas de ideias (liberalismo, neoliberalismo, marxismo, cristianismo), bem como com orientações e visões disciplinares. De qualquer modo, é possível vislumbrar alguns deslocamentos interculturais, e os dos Iny é o da retomada de saberes milenares, e da atualização das experiências ancestrais. Não se trata, portanto, da inclusão dos indígenas em nossas lógicas de produção e reprodução de saber, mas de abrir espaços de diálogo em que suas linguagens e seus processos de produção de conhecimento possam ser, igualmente, legitimados em suas escolas, mas também em outros contextos educativos, políticos e de interações diversas. 


\section{Referências}

CARNEIRO DA CUNHA, Manuela. "Cultura" e cultura: conhecimentos tradicionais e direitos intelectuais. In:__. Cultura com aspas e outros ensaios. São Paulo: Cosac Naify, 2009. p. 311-373.

KARAJÁ, Leandro Lariwana. Caderno de Estágio. Goiânia: UFG/Núcleo Takinahaky de Formação Superior de Professores Indígenas/Curso de Educação Intercultural, 2011.

KARAJÁ, Kuhanama. Caderno de Estágio. Goiânia: UFG/Núcleo Takinahaky de Formação Superior de Professores Indígenas/Curso de Educação Intercultural, 2011.

KARAJÁ, Txiarawa. Caderno de Estágio. Goiânia: UFG/Núcleo Takinahaky de Formação Superior de Professores Indígenas/Curso de Educação Intercultural, 2011.

KARAJÁ, Elly Mairu. Caderno de Estágio. Goiânia: UFG/Núcleo Takinahaky de Formação Superior de Professores Indígenas/Curso de Educação Intercultural, 2015.

NUNES, Eduardo S. A cruz e o itxe $(k) \grave{o}$ : mestiçagem, mistura e relação entre os Karajá de Buridina, Aruanã-GO. Artigo com base na Monografia de Graduação. UNB, 2009.

. No asfalto não se pesca. Parentesco, mistura e transformação entre os Karajá de Buridina (Aruanã-GO). Dissertação de mestrado. Brasília, PPGAS/DAN/UNB, 2012.

. Transformações karajá. Os "antigos" e o "pessoal de hoje" no mundo dos brancos. Tese de doutorado. Brasília, PPGAS/DAN/UNB, 2016.

OLIVEIRA WAHUKÁ, Sinvaldo. A vida do jovem iny. Projeto de pesquisa, 2015. (manuscrito).

PIMENTEL DA SILVA, Maria do Socorro. Resistência e retomada da língua e do patrimônio Cultural Karajá de Buridina. Revista Linguística. Rio de Janeiro, v. 13, n. 1, p. 231-244, 2017.

- Pedagogia da retomada: descolonização de saberes. Revista Articulando e Construindo Saberes. Goiânia, v. 2, n. 1, p. 204-2015, 2017.

Recebido para publicação em abril de 2018 .

Aceito para publicação em maio de 2018. 